\title{
MENSAGENS DE TEXTO DE CELULAR PARA SUPORTE AO ISOLAMENTO DOMICILIAR DE CASOS SUSPEITOS DE COVID-19
}

\section{CELL PHONE TEXT MESSAGES TO SUPPORT HOME ISOLATION OF SUSPECTED CASES OF COVID-19}

\author{
Andressa Suelly Saturnino de Oliveira ${ }^{1} *$ Katarina Milly Pinheiro de Sousa $^{2} *$ Ana de \\ Almeida Luis ${ }^{3} *$ Eduarda Maciel de Araujo ${ }^{4}$ Gilvan Ferreira Felipe ${ }^{5} *$ Ruth Carolina $^{*}$ \\ Queiroz Silvestre $^{6} *$ Henrique de Souza Freitas $^{7}$
}

\begin{abstract}
RESUMO
Objetivo: Relatar a experiência de uma intervenção educativa, usando mensagens de texto de telefonia celular, para suporte a pacientes com síndrome gripal (casos leves, suspeitos de Covid-19), que ensejam isolamento domiciliar. Métodos: Relato de experiência de ação de extensão de universidade pública, executada de outubro de 2020 a julho de 2021, no Ceará. Trata-se de uma intervenção educativa, realizada com 50 pessoas, usando o Short Message Service de telefonia móvel. O relato descreve a criação de banco de mensagens de texto de telefonia celular e o envio das mensagens para suporte ao isolamento domiciliar. Resultados: Elaborou-se 10 mensagens de texto, com informações sobre quando e como utilizar máscaras, higienizar as mãos, cuidados com objetos pessoais, limpeza de superfícies, comportamento intradomicílio, descarte de lixo e agravamento dos sintomas. O envio das mensagens ocorreu nas primeiras 48 horas depois do comparecimento à unidade de saúde, sendo 5 a cada dia, com intervalo de 2 horas entre elas. No $7^{\circ}$ dia, o paciente recebeu ligação telefônica, avaliando os cuidados em relação ao isolamento domiciliar adotados. Orientou-se, em seguida, sobre as fragilidades identificadas. Considerações finais: As mensagens de texto foram úteis para oferecer suporte às pessoas que necessitam permanecer em isolamento domiciliar, por serem casos suspeitos de Covid-19. Pela necessidade de diminuir a transmissão da doença, oferecer informações corretas aos pacientes, para autogerenciamento do isolamento, parece ser estratégia que se soma às orientações dadas nas unidades de saúde, durante as consultas e/ou por teleatendimento.

Palavras-chave: Covid-19; Envio de Mensagens de Texto; Isolamento de Pacientes; Educação em Saúde; Telemedicina.
\end{abstract}

\begin{abstract}
Objective: To report the experience of an educational intervention, using cell phone text messages, to support patients with flu-like illness (mild cases, suspected of Covid-19), who experience home isolation. Methods: Experience report of an extension action of a public university, carried out from October 2020 to July 2021, in Ceará. It is an educational intervention, carried out with 50 people, using the Short Message Service of mobile telephony. The report describes the creation of a cell phone text message bank and the sending of messages to support home isolation. Results: 10 text messages were elaborated, with information about when and how to use masks, hand hygiene, care with personal objects, cleaning surfaces, intra-household behavior, garbage disposal and worsening of symptoms. Messages were sent within the first 48 hours after attending the health unit, 5 each day, with an interval of 2 hours between them. On the 7 th day, the patient received a phone call, evaluating the care taken in relation to home isolation. Then, he was guided on the identified weaknesses. Final considerations: Text messages were useful to support people who need to remain in isolation at home, as they are suspected cases of Covid-19. Due to the need to reduce the transmission of the disease, offering correct information to patients, for self-management of isolation, seems to be a strategy that adds to the guidelines given in health units, during consultations and/or through telecare.
\end{abstract}

Keywords: Covid-19; Text Messaging; Patient Isolation; Health Education; Telemedicina.

\footnotetext{
${ }^{1}$ Universidade da Integração Internacional da Lusofonia Afro-Brasileira (Unilab), Redenção, Brasil. ORCID: https://orcid.org/00000002-2675-5159

${ }^{2}$ Universidade da Integração Internacional da Lusofonia Afro-Brasileira (Unilab), Redenção, Brasil. ORCID: https://orcid.org/00000002-3573-5643

${ }^{3}$ Universidade da Integração Internacional da Lusofonia Afro-Brasileira (Unilab), Redenção, Brasil. ORCID: https://orcid.org/00000003-4406-8827

${ }^{4}$ Universidade da Integração Internacional da Lusofonia Afro-Brasileira (Unilab), Redenção, Brasil. ORCID: https://orcid.org/0000$\underline{0003-3980-9977}$

${ }^{5}$ Universidade da Integração Internacional da Lusofonia Afro-Brasileira (Unilab), Redenção, Brasil. ORCID: https://orcid.org/00000003-0674-4396

${ }^{6}$ Universidade da Integração Internacional da Lusofonia Afro-Brasileira (Unilab), Redenção, Brasil. ORCID: https://orcid.org/00000001-6081-088X

${ }^{7}$ Universidade da Integração Internacional da Lusofonia Afro-Brasileira (Unilab), Redenção, Brasil. ORCID: https://orcid.org/0000$\underline{0002-2238-440 X}$
} 


\section{INTRODUÇÃO}

O mundo vive em cenário de onipresença de telefones celulares. Estes passaram a ser as principais formas de comunicação à distância há algum tempo, pela quantidade de pessoas que os têm e pela facilidade de acesso. Assim, não é difícil entender o motivo do interesse de uso desses dispositivos como recurso para a saúde. Mesmo antes da Pandemia de Covid-19, em 2020, a saúde móvel (mHealth) já era realidade.

A Organização Mundial da Saúde (OMS) define mHealth como uma prática de saúde pública suportada por dispositivos móveis. Há potencial para facilitar o acesso a diagnósticos clínicos e aconselhamento sobre tratamento. Detalhando as possibilidades de uso, podem ser citados: apoio ao diagnóstico clínico e/ou tomada de decisão; melhoria dos resultados clínicos de tratamentos, por meio de mudança de comportamento e aumento da adesão do paciente e cumprimento do tratamento; atuação como terapêutica digital autônoma; e oferecimento de educação relacionada a doenças ${ }^{(1)}$.

Ainda, mHealth tem o potencial de reduzir o tempo de espera por consultas e de diminuir a necessidade de se encontrar com um profissional de saúde pessoalmente. Consequentemente, as intervenções de mHealth têm o potencial de diminuir a carga de trabalho dos profissionais, ser mais econômica para a prática clínica e encorajar o autocuidado $^{(2)}$.

$$
\text { Uma das ferramentas para }
$$
implementação de mHealth é o Short Message Service (SMS), ou seja, o envio de mensagens de texto. A comunicação por esse serviço é objetiva e rápida e não exige que os participantes se comuniquem simultaneamente. É uma forma de comunicação neutra, pois funciona em qualquer telefone celular, sem necessidade de internet, tornando-a facilmente acessível para muitos $^{(3)}$.

No contexto de Pandemia de Covid19, pela necessidade de alcance de muitas pessoas, essa tecnologia pode ser utilizada para suporte ao cuidado oferecido nos serviços de saúde. Neste capítulo, a intenção é compartilhar uma experiência de uso de SMS para suporte ao isolamento domiciliar de casos suspeitos de Covid-19, identificados na Atenção Básica. Tal experiência surgiu da necessidade de monitoramento padronizado e regular, para que os usuários não ficassem "abandonados" depois de deixarem a unidade de saúde.

Verifica-se, então, a relevância da busca de novas estratégias de suporte à educação em saúde de pessoas com Covid-19 para melhoria dos índices de adesão ao isolamento domiciliar, além de divulgar experiências exitosas no uso dessas tecnologias, para estimular sua incorporação à 
oferta de cuidados. Acredita-se que a telefonia móvel pode conferir complementaridade ao atendimento de saúde realizado nos serviços de saúde, podendo ser integrada à oferta tradicional de cuidados em saúde ${ }^{(4)}$.

A partir dessas premissas, este estudo foi desenvolvido com o objetivo de relatar a experiência de uma intervenção educativa, usando mensagens de texto de telefonia celular, para suporte a pacientes com síndrome gripal (casos leves, suspeitos de Covid-19), que ensejam isolamento domiciliar.

\section{MÉTODOS}

Trata-se de relato de experiência de uma ação de extensão, vinculada a uma pesquisa do Instituto de Ciências da Saúde da Universidade da Integração Internacional da Lusofonia Afro-Brasileira (Unilab), realizada de outubro de 2020 a julho de 2021, em município do interior do Ceará.

A ação ocorreu numa unidade de saúde onde são encaminhadas as pessoas que necessitam de testagem, por serem casos suspeitos de Covid-19. Enquanto não possuem confirmação laboratorial, são diagnosticadas com síndrome gripal, caso leve, suspeito de Covid-19. Embora sejam casos suspeitos, tais pessoas requerem acompanhamento de profissionais de saúde da atenção básica, a cada 24 ou 48h, por meio de telemonitoramento, até que seja completado o período recomendado de isolamento domiciliar (caso o teste seja positivo ou até que o teste negativo seja informado).

Essa ação de extensão foi realizada por uma equipe de dez pessoas, docentes e discentes da Unilab, semanalmente. Foram convidadas pessoas que compareciam à unidade de saúde, que tinham: recebido diagnóstico de Síndrome Gripal (suspeita de Covid-19 / caso leve), com indicação de isolamento domiciliar; idade igual ou superior a 18 anos; alfabetizados; aparelho celular de uso pessoal; conseguiam ler mensagem de texto a partir do próprio telefone celular.

Optou-se por dividir este relato em duas partes para facilitar a compreensão da intervenção educativa. Consiste no(a): 1) Criação de banco de mensagens de texto de telefonia celular e 2) Envio das mensagens de texto para suporte ao isolamento domiciliar.

\section{RESULTADOS E DISCUSSÃO}

\section{Criação de banco de mensagens de texto de telefonia celular}

A elaboração das mensagens de texto ocorreu no segundo semestre de 2020. Foi realizado levantamento, em documento publicado pelo Ministério da Saúde, das informações para essa finalidade. $\mathrm{O}$ documento é o Protocolo de Manejo Clínico do Coronavírus (Covid-19) na Atenção Primária à Saúde - Versão 9. Na publicação, há uma lista de 17 medidas de isolamento 
domiciliar e cuidados domésticos para todos pacientes com diagnóstico de síndrome gripal, as quais são divididas em três finalidades: isolamento do paciente, precauções ao cuidador e precauções gerais ${ }^{(5)}$.

Após esse levantamento, discutiu-se sobre a quantidade de mensagens e os horários de envio, de modo a não sobrecarregar o paciente com informações. Deveria haver tempo suficiente, entre as mensagens, para que ele pudesse refletir sobre a informação recebida. Além disso, o envio das mensagens deveria ocorrer em horário comercial (8-17h) e nos primeiros dias após comparecimento ao serviço de saúde, para levar o máximo de informação possível logo no início do período de isolamento e possibilitar a aplicação do que foi aprendido até o final deste. Dessa forma, optou-se por enviar 10 mensagens, nas primeiras $48 \mathrm{~h}$ depois do comparecimento à unidade de saúde, sendo 5 a cada dia, com intervalo de 2 horas entre elas.

Passou-se à elaboração das mensagens, a partir das orientações contidas no Protocolo, o qual se baseou no $W H O$ Technical Guidance - Patient Management Coronavirus Disease 2019(6). As 17 medidas constantes foram agrupadas em 10 instruções para isolamento, as quais foram transformadas em mensagens de texto, que continham 160 caracteres, contando os espaços. Todas as mensagens foram precedidas de "Equipe de pesquisa Covid19”, para que o paciente reconhecesse o remetente das mensagens, mesmo que não tivesse cadastrado o número de telefone em sua agenda eletrônica.

As mensagens elaboradas foram submetidas à apreciação de três enfermeiros, com título de doutorado, docentes de cursos de graduação em saúde de uma universidade pública, os quais realizam pesquisas na atenção básica. Na avaliação, verificaram se o conteúdo das mensagens contemplava as orientações básicas suficientes para manter o isolamento corretamente e se a linguagem era acessível a qualquer pessoa. Solicitaram substituição de algumas palavras por sinônimos, que fossem de mais fácil compreensão. Também recomendaram numerar as mensagens, para que o destinatário pudesse compreender a ordem de recebimento, em caso de atraso de envio pela operadora de telefonia celular. Todos os ajustes solicitados foram efetuados. $\mathrm{O}$ esquema de envio e as mensagens foram apresentados no Quadro 1. 
Quadro 1 - Banco de mensagens de texto da pesquisa. Acarape, Ceará, Brasil, 2021.

(Continua)

\begin{tabular}{|c|c|c|}
\hline DIA & HORÁRIO & MENSAGEM \\
\hline \multirow{5}{*}{1} & $8 \mathrm{~h}$ & $\begin{array}{l}\text { [EQUIPE DE PESQUISA COVID-19] 1. Evite sair de casa, } \\
\text { receber visitas e ter contato com animais domésticos. Caso o } \\
\text { faça, lave as mãos antes e após contato. }\end{array}$ \\
\hline & $10 \mathrm{~h}$ & $\begin{array}{l}\text { [EQUIPE DE PESQUISA COVID-19] 2. Evite contato com } \\
\text { outras pessoas dentro de casa. Mantenha-se no quarto } \\
\text { individual, arejado, com a porta fechada. }\end{array}$ \\
\hline & $12 \mathrm{~h}$ & $\begin{array}{l}\text { [EQUIPE DE PESQUISA COVID-19] 3. Use um banheiro } \\
\text { individual. Se não, limpe-o sempre após o uso com água } \\
\text { sanitária ou álcool. }\end{array}$ \\
\hline & $14 \mathrm{~h}$ & $\begin{array}{l}\text { [EQUIPE DE PESQUISA COVID-19] 4. Toalhas e utensílios } \\
\text { de higiene pessoal não devem ser compartilhados com as } \\
\text { demais pessoas da sua casa. }\end{array}$ \\
\hline & $16 \mathrm{~h}$ & $\begin{array}{l}\text { [EQUIPE DE PESQUISA COVID-19] 5. Evite compartilhar } \\
\text { objetos dentro de casa. Louças e roupas usadas devem ser } \\
\text { lavadas como habitualmente. }\end{array}$ \\
\hline
\end{tabular}

Fonte: Os autores.

Quadro 1 - Banco de mensagens de texto da pesquisa. Acarape, Ceará, Brasil, 2021.

(Conclusão)

\begin{tabular}{|l|l|l|}
\hline DIA & HORÁRIO & \multicolumn{1}{|c|}{ MENSAGEM } \\
\hline \multirow{2}{*}{2} & $8 \mathrm{~h}$ & $\begin{array}{l}\text { [EQUIPE DE PESQUISA COVID-19] 6. Lave as mãos com } \\
\text { frequência com água e sabão durante 20 segundos ou use álcool } \\
\text { em gel. }\end{array}$ \\
\cline { 2 - 3 } & $10 \mathrm{~h}$ & $\begin{array}{l}\text { [EQUIPE DE PESQUISA COVID-19] 7. Evite tocar nos olhos, } \\
\text { nariz e boca com as mãos sujas. Todos que moram com você } \\
\text { devem reforçar a higiene das mãos. }\end{array}$ \\
\hline
\end{tabular}




\begin{tabular}{|l|l|l|}
\hline $12 \mathrm{~h}$ & $\begin{array}{l}\text { [EQUIPE DE PESQUISA COVID-19] 8. Use máscara sempre } \\
\text { que entrar em contato com outras pessoas. Ao tossir ou espirrar, } \\
\text { cubra a boca com o braço ou um lenço de papel e, após isso, } \\
\text { jogue no lixo. }\end{array}$ \\
\hline $14 \mathrm{~h}$ & $\begin{array}{l}\text { [EQUIPE DE PESQUISA COVID-19] 9. Coloque todo o lixo, } \\
\text { incluindo lenços de papel e máscaras, em um saco e feche-o } \\
\text { quando estiver cheio, colocando, em seguida, dentro de outro } \\
\text { saco bem amarrado. } \\
\text { [EQUIPE DE PESQUISA COVID-19] 10. Vigie os sintomas. } \\
\text { Em caso de agravamento, vá para uma unidade de saúde usando } \\
\text { máscara a todo momento. Mantenha todos os cuidados por 14 } \\
\text { dias ou até a confirmação de exame negativo. }\end{array}$ \\
\hline
\end{tabular}

Fonte: Os autores.

O formato das mensagens de texto obedeceu à política de SMS para membros da força de trabalho da área de saúde. Essa política define a estratégia como envio de mensagens de texto de 160 caracteres, por meio de telefone celular ou de interface baseada na web, para um ou mais destinatários de telefone celular. Como precaução administrativa, o envio precisa ser consentido, documentado e não conter nome/sobrenome do destinatário no corpo do texto. A política define como boa prática o texto curto e conciso, para que os 160 caracteres sejam mantidos, evitando transição para duas mensagens ${ }^{(3)}$.

Elaborou-se, também, uma mensagem-teste, para ser enviada no momento de abordagem ao paciente, para averiguar se ele sabia utilizar o SMS do próprio celular e para oportunizá-lo a salvar o número de telefone da equipe de pesquisa, se desejasse, a qual enviaria as 10 mensagens a partir do dia seguinte. A mensagem era "[EQUIPE DE PESQUISA COVID-19] Mensagem de teste para participação na pesquisa."

Elaboradas a partir do Protocolo $^{(5)}$, as 10 mensagens têm conteúdo que pretende estimular o desenvolvimento de habilidades para autogerenciamento do isolamento domiciliar de forma simples e eficaz. As mensagens abordam informações sobre quando e como utilizar máscaras, higienizar as mãos, cuidados com objetos pessoais, limpeza de superfícies, comportamento 
intradomicílio, descarte de lixo e agravamento dos sintomas.

Para o paciente com suspeita de Covid-19, por ser caso leve de síndrome gripal, é importante estimular o autogerenciamento do isolamento, pois não haverá presença física do profissional de saúde até o término do isolamento domiciliar (exceto pelas ligações telefônicas de monitoramento a cada 24/48h). Assim, é necessário utilizar estratégia de cuidado que seja centrada na pessoa, para que ela possa entender sua participação no cuidado, a fim de evitar transmissão da doença intradomicílio ou para outras pessoas fora dele. As mensagens oferecem conhecimento de forma não-invasiva, que se integra ao que o paciente já sabe e permite a tomada de decisão de modo consciente. A literatura científica reconhece que estimular essas habilidades leva à melhoria da autoeficácia ${ }^{(7)}$.

\section{Envio das mensagens de texto para suporte ao isolamento domiciliar}

Ao concluírem o fluxo de atendimento na unidade de saúde para pessoas com suspeita de Covid-19, os pacientes foram abordados por membros da equipe, que os convidaram a participar. Com a anuência (registrada e documentada) em local reservado, o participante respondeu a um formulário de cadastramento com dados básicos (nome, número de telefone celular para contato, bairro de residência). A mensagem-teste foi enviada e o participante foi solicitado a procurá-la no telefone celular e ler.

Ainda na unidade de saúde, o membro da equipe da ação conversava com o participante sobre os cuidados em relação ao isolamento domiciliar adotados desde que os sintomas iniciaram. As respostas foram registradas em instrumento de avaliação préintervenção. Até junho de 2021, 50 pessoas responderam a esse instrumento.

A mesma pessoa que abordou o participante na unidade de saúde fez o envio das mensagens de texto, programando para que fossem recebidas nos horários planejados. A fim de avaliar como os cuidados estavam sendo implementados e se havia necessidade de reforçar alguma informação sobre os cuidados com o isolamento domiciliar, no $7^{\circ}$ dia após o comparecimento à unidade de saúde, pessoa diferente da que abordou o paciente na unidade fazia uma ligação telefônica para ele, perguntando como ele estava se sentindo, como foram os dias após comparecimento à unidade de saúde e avaliando, novamente, os cuidados em relação ao isolamento domiciliar adotados, entretanto, referindo-se ao período posterior à ida ao serviço de saúde. Após registro das respostas em formulário, o membro da equipe explicava os pontos que verificou não terem sido adotados pelo participante.

É importante ressaltar que a intervenção também teve a intenção de 
favorecer a disseminação de informações. A ligação do $7^{\circ}$ dia, mesmo ocorrendo em período de finalização do isolamento para algumas pessoas, serviu para tirar dúvidas e reforçar comportamentos corretos, que poderiam ser compartilhados por eles com outras pessoas. Isso, indiretamente, contribui para diminuir a disseminação da doença, pois são informações corretas, que podem ser compartilhadas com familiares, amigos, vizinhança e no ambiente de trabalho.

É preciso lembrar que o envio de mensagens de texto é estratégia de suporte, não substitutiva do cuidado ofertado na UBS, presencialmente ou por teleatendimento, por demanda espontânea, após aparecimento dos primeiros sintomas. A consulta do profissional de saúde continua sendo necessária, para avaliação, diagnóstico (de síndrome gripal ou confirmação de Covid-19) e para acompanhamento por ligações telefônicas, até o término do período de isolamento domiciliar recomendado.

Toda estratégia de suporte se soma ao cuidado ofertado na UBS pelas equipes de Saúde da Família. Isso porque a atenção clínica individual permanece indispensável para orientar os casos suspeitos quanto ao isolamento e reconhecimento dos sinais de alerta, identificar pacientes que não podem ser cuidados no domicílio, monitorar os casos suspeitos quanto à evolução clínica, realizar teleatendimento para casos mais complexos e solicitar remoção para uma unidade hospitalar ao identificar sinais de agravamento ${ }^{(8)}$.

\section{CONSIDERAÇÕES FINAIS}

No relato de experiência apresentado, verificou-se que o SMS foi ferramenta útil para oferecer suporte às pessoas que necessitam permanecer em isolamento domiciliar, por serem casos suspeitos de Covid-19. Pela necessidade de diminuir a transmissão da doença, oferecer informações corretas aos pacientes, para que possam tomar decisões conscientes para autogerenciamento do isolamento, parece ser estratégia que se soma às orientações dadas nas unidades de saúde, durante as consultas e/ou por teleatendimento.

O banco de mensagens de texto criado reflete o conteúdo das orientações contidas em documento publicado pelo Ministério da Saúde, mas não tem a finalidade de substituir o cuidado ofertado na atenção básica para pacientes com suspeitas ou confirmação de Covid-19. Serve, exclusivamente, para suporte. Trata-se de 10 mensagens de texto, que versam sobre como utilizar máscaras, higienizar as mãos, cuidados com objetos pessoais, limpeza de superfícies, comportamento intradomicílio, descarte de lixo e sintomas.

Embora tenha como limitação a utilização, nesta experiência, apenas no contexto da atenção básica, acredita-se que 
seu uso pode ocorrer em qualquer cenário de saúde em que precisem ser reforçadas informações para sintomáticos respiratórios, que necessitem de isolamento domiciliar. Outra limitação corresponde à história natural da doença, que ainda está em curso. Informações contidas nas mensagens podem precisar de ajustes futuros para o caso de mudanças de recomendações de órgãos de saúde nacionais e internacionais. Entretanto, para a situação de Pandemia de Covid-19 conhecida até então, os conteúdos das mensagens de texto contribuem para prevenção da disseminação da doença e, portanto, de seu controle.

\section{REFERÊNCIAS}

1. Rowland SP, Fitzgerald JE, Holme T, Powell J, McGregor A. What is the clinical value of mHealth for patients?. Npj Digital Medicine [Internet]. 2020 [cited 2021 Aug 25];3(4):1-6. Available from: https://doi.org/10.1038/s41746019-0206-X

2. Rathbone AL, Prescott J. The Use of Mobile Apps and SMS Messaging as Physical and Mental Health Interventions: Systematic Review. Journal of Medical Internet Research [Internet]. 2017 [cited 2021 Aug 25];19(8):1-13. Available from: https://doi.org/10.2196/jmir.7740

3. Storck L. Policy Statement: Texting in Health Care. On-Line Journal of Nursing Informatics [Internet]. 2017 [cited 2021 Jul 30];21(1) Available from: https://www.proquest.com/openview/1b867a1592 c570aaafe597b89ef0d45a/1?pq-

origsite $=$ gscholar\&cbl $=2034896$

4. Bobrow K, Brennan T, Springer D, Levitt NS, Rayner B, Namane M, et al. Efficacy of a text messaging (SMS) based intervention for adults with hypertension: protocol for the StAR (SMS Text-message Adherence suppoRt trial) randomised controlled trial. BMC Public Health [Internet]. 2014 [cited 2021 Aug 25];14(28) Available from: https://doi.org/10.1186/14712458-14-28

5. Brasil, Ministério da Saúde. Secretaria de Atenção Primária à Saúde. Protocolo de Manejo Clínico do Coronavírus (COVID-19) na Atenção Primária à Saúde [Internet]. 9. Brasília: Ministério da Saúde; 2020 [cited 2021 Aug 25]. Available from:

https://portaldeboaspraticas.iff.fiocruz.br/wpcontent/uploads/2020/05/20200504_ProtocoloMa nejo ver09.pdf

6. World Health Organization (WHO). Coronavirus disease (COVID-19) technical guidance: Patient management [Internet]. [place unknown]: WHO; 2020 [cited 2021 Aug 27]. Available

from: https://www.who.int/emergencies/diseases/novelcoronavirus-2019/technical-guidance/patientmanagement

7. Dineen-Griffin S, Garcia-Cardenas V, Williams K, Benrimoj SI. Helping patients help themselves: A systematic review of self-management support strategies in primary health care practice. PLoS ONE [Internet]. 2019 [cited 2021 Aug 25];14(8):1-29. Available from: https://doi.org/10.1371/journal.pone.0220116

8. Daumas RP, Silva GA, Tasca R, Leite IC, Brasil P, Greco DB, et al. O papel da atenção primária na rede de atenção à saúde no Brasil: limites e possibilidades no enfrentamento da COVID-19. Cadernos de Saúde Pública [Internet]. 2020 [cited 2021 Aug 25];36(6) Available from: http://dx.doi.org/10.1590/0102-311X00104120

\section{Autor correspondente}

Andressa Suelly Saturnino de Oliveira Endereço: Rua Deputado João Pontes, 900, apartamento 204A, bairro Fátima, Fortaleza, Ceará, Brasil, CEP: 60.040-430

Telefone: (85) 99928-9695

E-mail: andressasuelly@unilab.edu.br

Submissão: 2021-08-31

Aprovado: 2021-09-14 